\title{
Closed Loop V/f Speed Control of Multilevel Inverter Fed Induction Motors Using PID and Fuzzy Logic Controllers
}

\author{
Aravinda Shilpa Konathala*, Mamillapalli Rose Mary ${ }^{\dagger}$, Bade Mounica, \\ Gudla Meghana, Jyothula Renuka Devi \\ Department of Electrical Engineering, Andhra University College of Engineering for Women, Andhra University, \\ Andhra Pradesh, India \\ Received 08 August 2021; received in revised form 21 September 2021; accepted 22 September 2021
}

DOI: https://doi.org/10.46604/peti.2021.8232

\begin{abstract}
The Volts per Hertz (V/f) speed control method makes induction motors available to be used in variable speed applications. However, the great harmonic distortion in supply voltage is a major issue of this method. Therefore, this study focuses on decreasing the harmonic distortion in the supply to induction motors. For that, the use of thirty-one-level multilevel inverters (MLIs) is investigated. Another drawback of the V/f speed control method is the use of proportional-integral-derivative (PID) controllers as speed controllers, which are difficult to be tuned precisely. To overcome this, the use of fuzzy logic controllers is investigated. The whole model is developed and simulated in MATLAB/SIMULINK by varying two variables, i.e., reference speed and load torque, one at a time using each controller. The observations for the changes in speed, torque, stator current, and supply voltage to the induction motors are made. The system's performance using fuzzy logic controllers is found superior.
\end{abstract}

Keywords: multilevel inverter, induction motor, constant V/f speed control, PID controller, fuzzy logic controller

\section{Introduction}

Induction motors have been widely used since the day of their invention. They are employed in almost all industrial, robotic, and domestic applications because of their advantages, e.g., robustness, inexpensiveness, simpleness and lightness in construction, maintenance-free operation, etc. Although they possess some disadvantages like time-varying and non-linear dynamics, the advantages surpass the disadvantages. Hence, they are used in various applications including fans, blowers, cranes, traction, electric vehicles, conveyors, etc.

Induction motors are remarkably known as constant speed motors because the drop in their speed from no-load to full-load is small. This limited their demand for constant speed applications. The advancements of the power electronics field paved a path for the speed control of induction motors. Many speed control methods were developed to control the speed of induction motors to use their advantages even in variable speed applications. The variable voltage and variable frequency method or the Volts per Hertz (V/f) speed control method is found efficient among all the speed control methods. Using this method, the speed of the motors can be controlled smoothly over a wide range [1-3]. The motors are fed from a voltage source inverter (VSI) to obtain the variable voltage and variable frequency supply. The VSI produces a two- or three-level voltage output that contains a greater number of harmonics. Due to this, the motors develop a pulsating torque which is undesirable and needs to be overcome. To remove the harmonics from the inverter output, the inverter output is passed through a filter, whose

* Corresponding author. E-mail address: aravindashilpacf@ andhrauniversity.edu.in

† Corresponding author. E-mail address: rosemarymamillapalli@gmail.com 
size and cost increase with voltage requirement, increasing the cost of the whole system. Chitra et al. [4] proposed that by employing a five-level cascaded H-bridge (CHB) multilevel inverter (MLI) in the place of a conventional VSI, the harmonic distortion and hence the torque pulsation can be reduced. The size of the filter, if employed, can also be reduced. However, their proposed method has some drawbacks, such as the increased number of switching devices and the increased complexity in the control circuit of the inverter. The use of five-level CHB MLI reduces the harmonic distortion in the inverter output as compared to the use of a VSI. However, it is high enough to cause heating of the motor winding.

Due to the non-linear nature of the induction motor control dynamics, an efficient control algorithm is required to control the speed of induction motors. The conventional controllers used for the induction motor speed control are proportional-integral (PI) controllers. However, because of the use of PI controllers, the overshoots of greater amplitude are observed in the speed response of induction motors, which requires a larger settling time to attain a steady state. Hence, proportional-integral-derivative (PID) controllers can be used to decrease the overshoots slightly and hence the settling time [5].

This study focuses on employing an MLI of a greater number of levels(thirty-one levels) to feed an induction motor for its variable frequency control so that an input supply of less harmonic distortion is obtained and the use of a filter can be avoided. Also, the use of a PI or PID controller as a speed controller causes overshoots, and the exact mathematical model of the system is needed for tuning. Hence, this study also focuses on investigating the use of a fuzzy logic controller, which has better performance than a PID controller as a speed controller.

\section{Variable Voltage and Variable Frequency Control}

If $f$ is supply frequency and $P$ is the number of stator poles, the synchronous speed $\left(\omega_{s}\right)$ of an induction motor is given by:

$$
\omega_{s}=\frac{4 \pi f}{P} \mathrm{rad} / \mathrm{s}
$$

Since the induction motor is an asynchronous motor, it cannot run at synchronous speed, i.e., the speed at which the stator field rotates. The difference between the synchronous speed and the rotor speed is called the slip speed. Hence, the rotor speed $\left(\omega_{r}\right)$ of the induction motor is given by:

$$
\omega_{r}=(1-s) \omega_{s} \mathrm{rad} / \mathrm{s}
$$

or

$$
\omega_{r}=(1-s) \frac{4 \pi f}{P} \mathrm{rad} / \mathrm{s}
$$

where $s$ is the slip. From the above equation, it is clear that the speed of the induction motor can be changed either by varying the number of poles, the slip, or the supply frequency. The speed controlled by varying the supply frequency is proved to be efficient. The equation for the stator induced electromotive force is given by:

$$
E=4.44 K \Phi T f \mathrm{~V}
$$

where $K$ and $T$ are constants. If only the supply frequency is varied without changing the supply voltage, then the air-gap flux of the induction motor varies. However, the induction motor is designed to operate at the knee point of the magnetizing characteristic. Therefore, if the flux increases beyond the rated value, then a larger amount of currents will be drawn by the motor to produce that flux. If the flux decreases below the rated value, the motor cannot develop the required torque. Hence, it is required to be ensured that the flux remains at the rated value. For that, the magnitude of the supply voltage has to be changed 
along with the supply frequency. Due to this reason, this method of speed control is called the variable voltage and variable frequency control or constant V/f control. However, the voltage is kept at some higher value for low frequencies to overcome the stator resistance drop [6].

To produce this voltage of variable magnitude and frequency, the induction motor is fed from a VSI. The VSI produces voltage with greater harmonic distortion due to which the pulsating torque is produced and the motor winding gets heated up. Thus, MLI is a suitable alternative producing an approximate sinusoidal output waveform with less harmonic distortion.

\section{Multilevel Inverter (MLI)}

MLI is a power electronic device that can provide the desired alternating current (AC) voltage levels at the output using multiple low direct current (DC) voltages as the inputs. MLI generates higher voltage waveforms from lower voltage components. The major purpose of MLI is to operate in high power applications using low-rating devices. Therefore, MLI is a preferred choice in industries for medium and high power applications. Multilevel power conversion was introduced more than twenty years ago.

Over the past years, the demand for MLIs is increasing gradually due to their advantages such as the output voltage with decreased harmonic content, the lower electromagnetic interference, and the decreased $d v / d t$ stress on the switches. Due to the reduction in the harmonic content, the voltage wave obtained from MLIs is almost sinusoidal; hence, a higher wave quality is obtained when compared to VSIs. MLIs are generally operated at lower switching frequencies when compared to VSIs; hence, the stresses on switches are also reduced. For low and medium voltage applications, the importance of MLIs is discovered in nearly every subject of electrical engineering together with renewable power systems, high voltage direct current (HVDC) applications, industrial drive applications, uninterruptible energy supplies, etc. MLIs are widely used in drives and different allied regions in industries.

Due to these advantages, numerous configurations of MLIs are being developed which may fall under one of the three basic topologies, i.e., flying-capacitor (FC), neutral-point-clamped (NPC), and CHB topologies, or a few hybrids of those [7-9]. Cascaded MLIs are further classified into two types, i.e., symmetric and asymmetric types, based on the magnitude of DC sources. The input DC sources have equal magnitude for the symmetric type while the DC sources have unequal magnitude for the asymmetric type. However, the asymmetric CHB MLI has more advantages because of its ability to produce a greater number of levels with a less number of components [10-11].

In this study, a thirty-one-level asymmetrical MLI is used to feed the motor. The topology contains 17 switches of which $S_{1}, S_{2}, S_{3}$, and $S_{4}$ form the first H-bridge, $S_{5}, S_{6}, S_{7}$, and $S_{8}$ form the second H-bridge, and $S_{9}, S_{10}, S_{11}$, and $S_{12}$ form the third H-bridge. This MLI is controlled by multicarrier sinusoidal pulse-width modulation [12]. The topology is shown in Fig. 1.

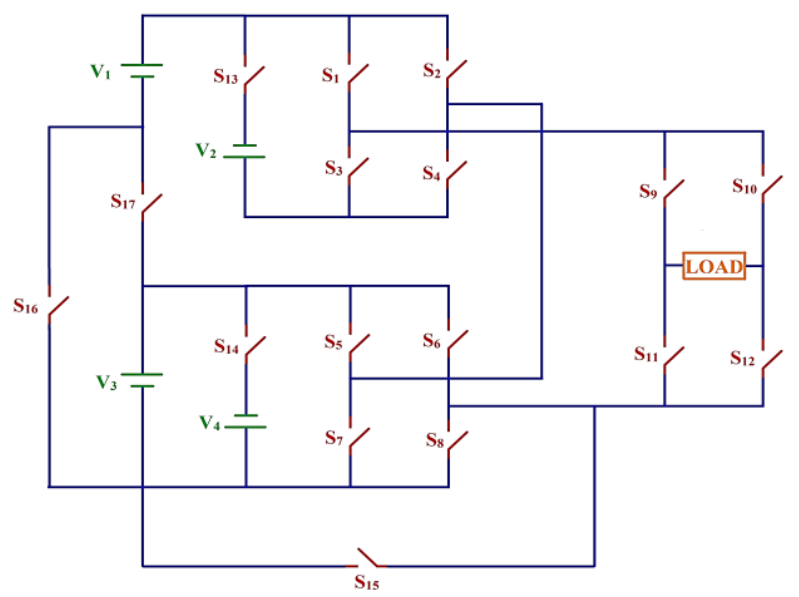

Fig. 1 Thirty-one-level asymmetrical MLI 
The above topology gives an output voltage with total harmonic distortion (THD) as low as $4.00 \%$ [12]. It is very much less when compared to the THD presented in the output voltage of a two- or three-level VSI. Since the THD is less, the drawbacks which occur by using the VSI in the V/f speed control can be overcome efficiently.

\section{Speed Controller}

To control the speed of the induction motor which has a highly non-linear dynamic behavior, a strenuous control algorithm is required. The most commonly used controllers for this purpose include PI controllers, proportional-derivative (PD) controllers, and PID controllers, or a combination of these. PID controllers are proved to be superior because they provide reliable and robust control if tuned properly. To set the parameters of these controllers, the plant model has to be linearized by complex mathematical calculations. Despite this effort, the values obtained are only approximate, and the variations that occur in the model due to the practical conditions add to the complexity. Further, decent performance is obtained only at one operating speed. The drawbacks mentioned above show a requirement for a more robust, reliable, cost-effective, and less complex speed controller. A fuzzy logic controller possessing all these qualities seems to be a better alternative for the conventional controller [13-17].

From the last three decades, the demand for fuzzy control has increased gradually because of its characteristics such as better non-linearity handling capability, knowledge-based algorithm, being independent from exact plant modeling, and having a control algorithm that replicates the human thought process. Along with these attributes, a fuzzy logic controller provides good response in stability, precision, and rapidity. Hence, this controller is simple to design and also to use as it requires almost no knowledge of complex mathematical calculations but a qualitative knowledge of the system.

\section{The Proposed Speed Control Model}

Fig. 2 shows the block diagram of the proposed closed-loop V/f speed control model of an induction motor. The main components of the system include a speed controller, a slip regulator, a flux controller, and an MLI supplying power to the induction motor.

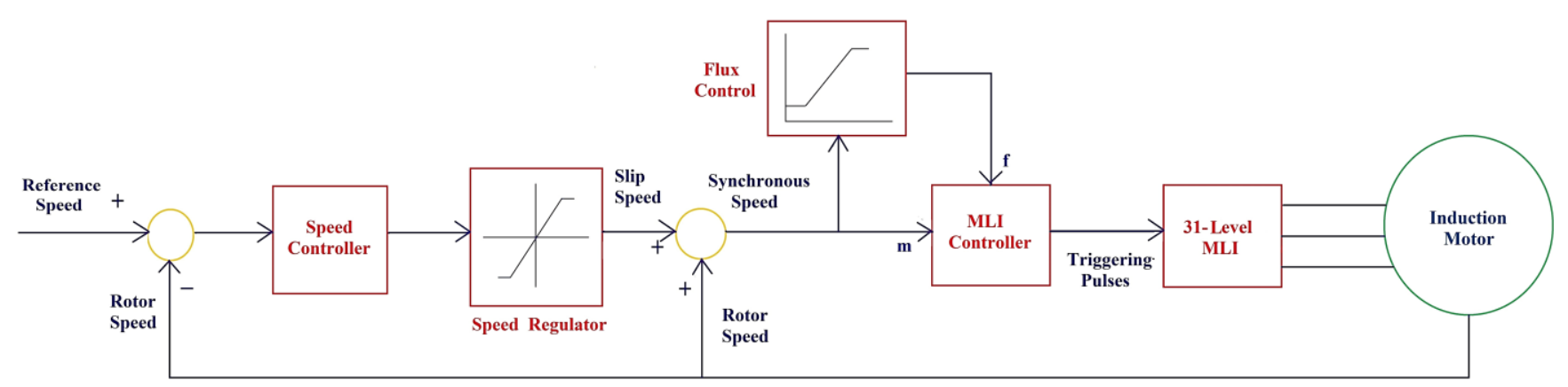

Fig. 2 Block diagram of the proposed model

As shown in Fig. 2, the actual speed of the rotor is compared with the reference speed in a comparator and a speed error is generated, which is the slip speed. This slip speed is passed through a speed controller which produces the output with reduced noise and good steady-state accuracy. When a PID controller is used, it performs proportional, integral, and derivative action on the speed error, and produces the controlled output.

Fig. 3 shows the block diagram of the fuzzy logic controller, which simulates the behaviour of the PID controller. When a fuzzy logic controller is used as a speed controller, it requires two inputs namely "error" and "derivative of error", which are normalized to match the fuzzifier limits. The inference system then processes these two fuzzy inputs using the fuzzy control rules and the database. These are given by the programmer based on the chosen membership function and fuzzy rule table 
which is shown in Table 1, to give the output fuzzy variable. The obtained fuzzy outputs are defuzzified by the defuzzifier to produce a crisp value, i.e., change-of-control. This value is integrated using an integrator and limited to a safe value using a saturation limiter. This value is then multiplied with suitable integral gain and then added to the change-of-control signal which is multiplied by a suitable derivative gain. This makes the fuzzy logic controller imitate a PID controller. The controlled output is then obtained from the fuzzy logic controller.

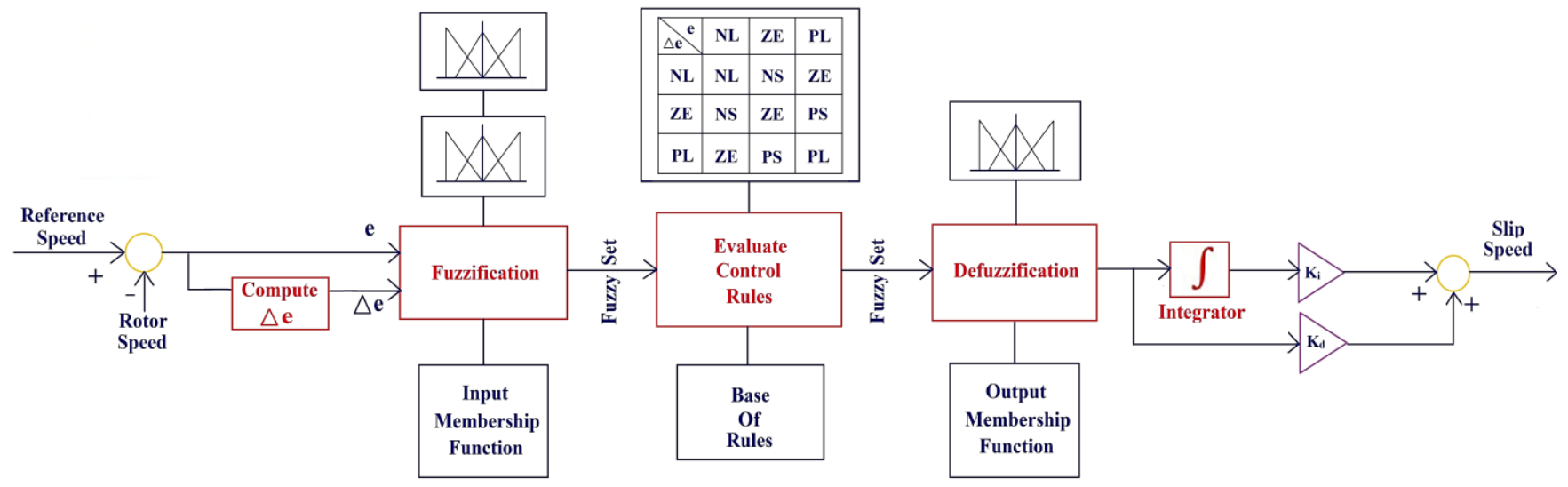

Fig. 3 Block diagram of fuzzy logic controller

Table 1 Fuzzy rule table for output

\begin{tabular}{|c|c|c|c|c|c|c|c|}
\hline$\Delta \mathbf{e}$ & $\mathbf{N L}$ & $\mathbf{N M}$ & $\mathbf{N S}$ & $\mathbf{Z E}$ & $\mathbf{P S}$ & $\mathbf{P M}$ & PL \\
\hline NL & NL & NL & NLM & NM & NMS & NS & ZE \\
\hline NM & NL & NLM & NM & NMS & NS & ZE & PS \\
\hline NS & NLM & NM & NMS & NS & ZE & PS & PMS \\
\hline ZE & NM & NMS & NS & ZE & PS & PMS & PM \\
\hline PS & NMS & NS & ZE & PS & PMS & PM & PLM \\
\hline PM & NS & ZE & PS & PMS & PM & PLM & PL \\
\hline PL & ZE & PS & PMS & PM & PLM & PL & PL \\
\hline
\end{tabular}

This controlled output, whether obtained from the PID controller or fuzzy logic controller, is fed to a slip regulator, which controls the slip, thereby limiting the operation of the motor in the stable region of torque-speed characteristics, i.e., from the synchronous speed to the speed corresponding to the maximum torque. Also, the stator currents and the torque produced are limited within the safe value by controlling the slip.

This controlled and regulated slip speed is added to the rotor speed, which gives the synchronous speed. The obtained synchronous speed is then converted into the respective frequency and fed to the flux control block, where the modulating signal of the required magnitude and frequency will be generated. This modulating signal is used to control the switching of the MLI which feeds the induction motor. Thus, the MLI shown in Fig. 1 produces a voltage of required magnitude and frequency. The motor runs at the reference speed specified, at the rated flux, and below the rated speed.

\section{Simulation Results and Discussion}

The proposed speed control model is simulated using MATLAB/SIMULINK tool, as shown in Fig. 4. A three-phase squirrel-cage induction motor of the rated voltage $400 \mathrm{~V}$ and speed $1500 \mathrm{rpm}$ is chosen. From the motor parameters, the slip-speed value corresponding to the maximum speed is $55.8 \mathrm{rps}$. Hence, this value is chosen as a limiting value in the slip regulator. To feed the induction motor, the DC sources in the three-phase MLI are selected to be $\mathrm{V}_{1}=22.6 \mathrm{~V}, \mathrm{~V}_{2}=43.2 \mathrm{~V}, \mathrm{~V}_{3}$ $=86.4 \mathrm{~V}$, and $\mathrm{V}_{4}=172.8 \mathrm{~V}$ so that a peak voltage of $\mathrm{V}_{1}+\mathrm{V}_{2}+\mathrm{V}_{3}+\mathrm{V}_{4}=325 \mathrm{~V}$ will be generated and its root mean square (RMS) value will be $230 \mathrm{~V}$ which is the required per phase voltage. Fig. 5 shows the simulation model of the MLI. 
As shown in Fig. 6, the flux control block limits the frequency to $50 \mathrm{~Hz}$, which is the rated frequency, and produces the modulating signal of the required frequency. The voltage is boosted to a slightly higher value at low frequencies to overcome the stator resistance drop. Fig. 7 shows the simulation model of the fuzzy logic controller. A PID-type fuzzy logic controller is developed using the Mamdani inference engine. The inference system consists of seven membership functions corresponding to the two inputs "error" and "change-of-error", and eleven membership functions corresponding to the output "change-of-control", as shown in Fig. 8.

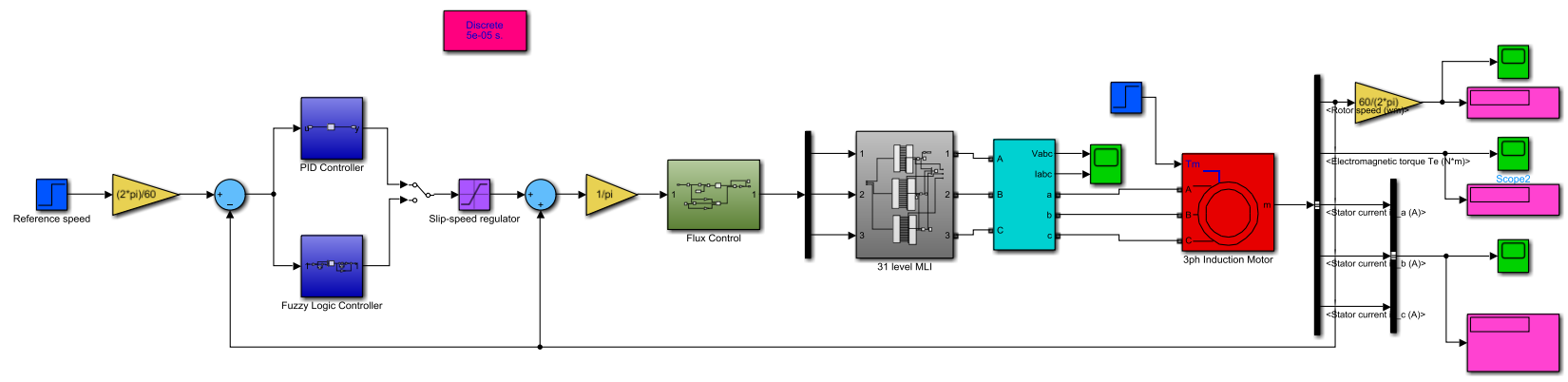

Fig. 4 Simulation model of the proposed speed control model

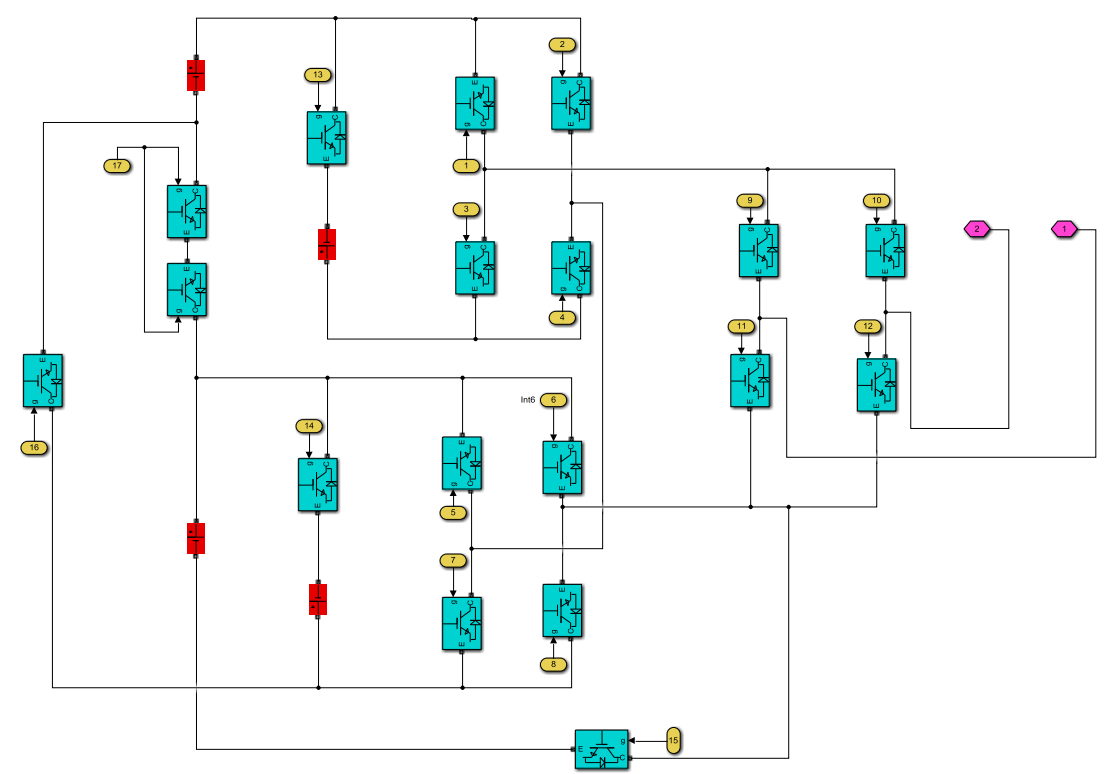

Fig. 5 Simulation model of the proposed thirty-one level MLI

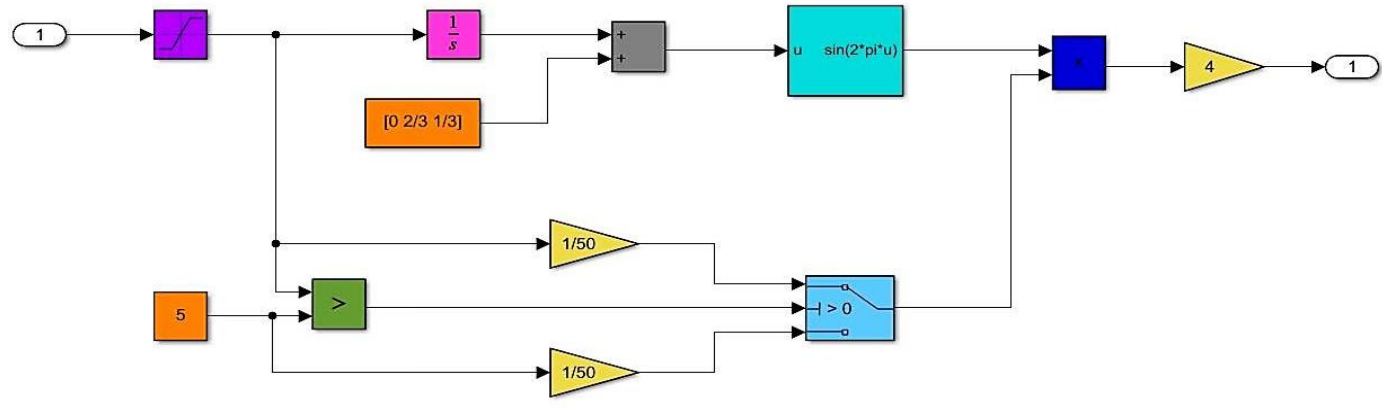

Fig. 6 Simulation model of flux control block

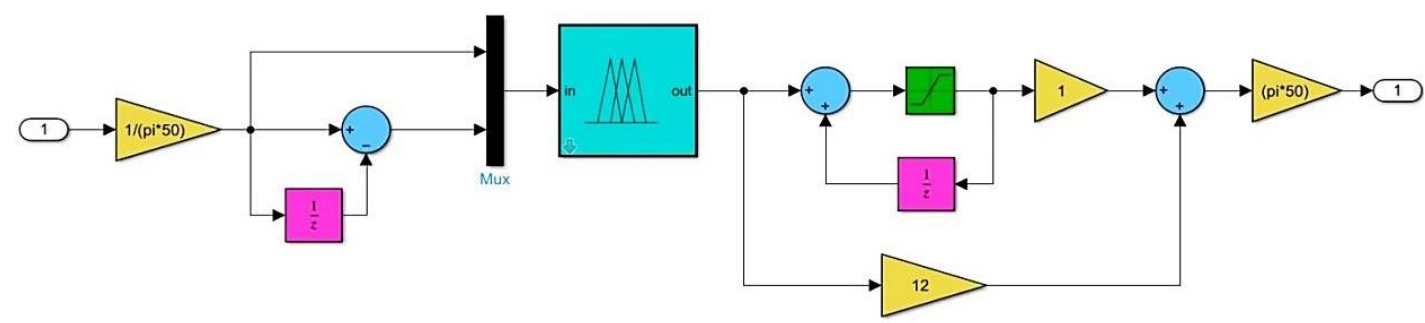

Fig. 7 Simulation model of fuzzy logic controller 


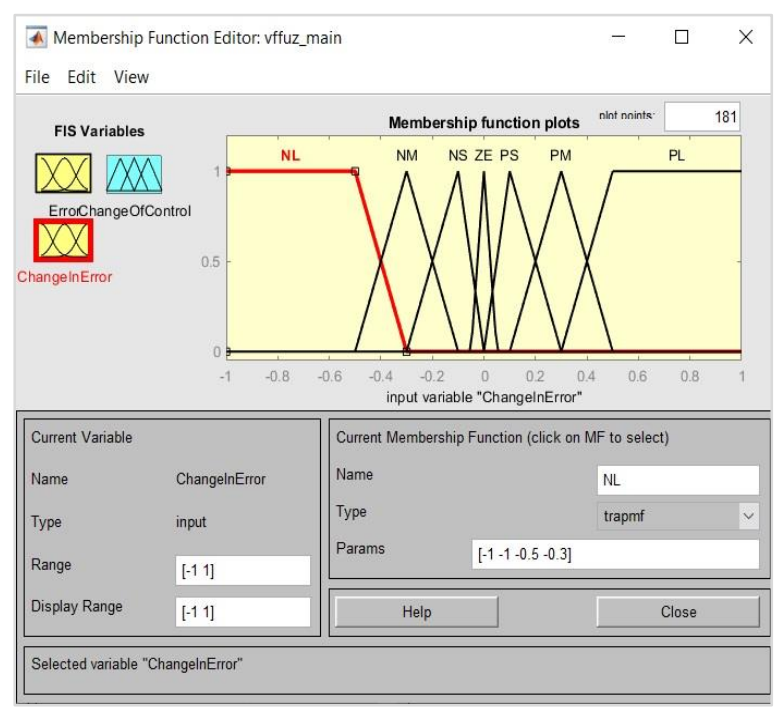

(a) Input membership functions

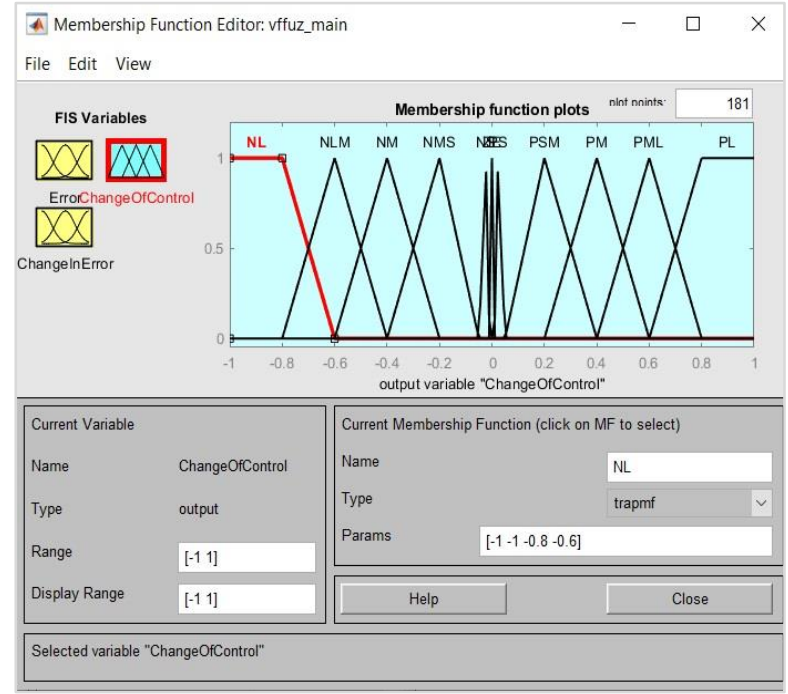

(b) Output membership functions

Fig. 8 Input and output membership functions of fuzzy logic controller

To test the viability of the proposed model, the model is simulated under two conditions using both PID and fuzzy logic controllers:

(1) Variable speed and constant load torque

(2) Constant speed and variable load torque

\subsection{Case 1: variable speed and constant load torque}

A constant load torque of $20 \mathrm{~N}-\mathrm{m}$ is kept on the motor, and the reference speed is changed stepwise from $1000 \mathrm{rpm}$ to $1400 \mathrm{rpm}$ at $t=2 \mathrm{sec}$ and then to $700 \mathrm{rpm}$ at $t=4 \mathrm{sec}$. The changes in speed response (Fig. 9), torque response (Fig. 10), stator currents (Figs. 11-12), and MLI output (Figs. 13-14) are noted as follows.

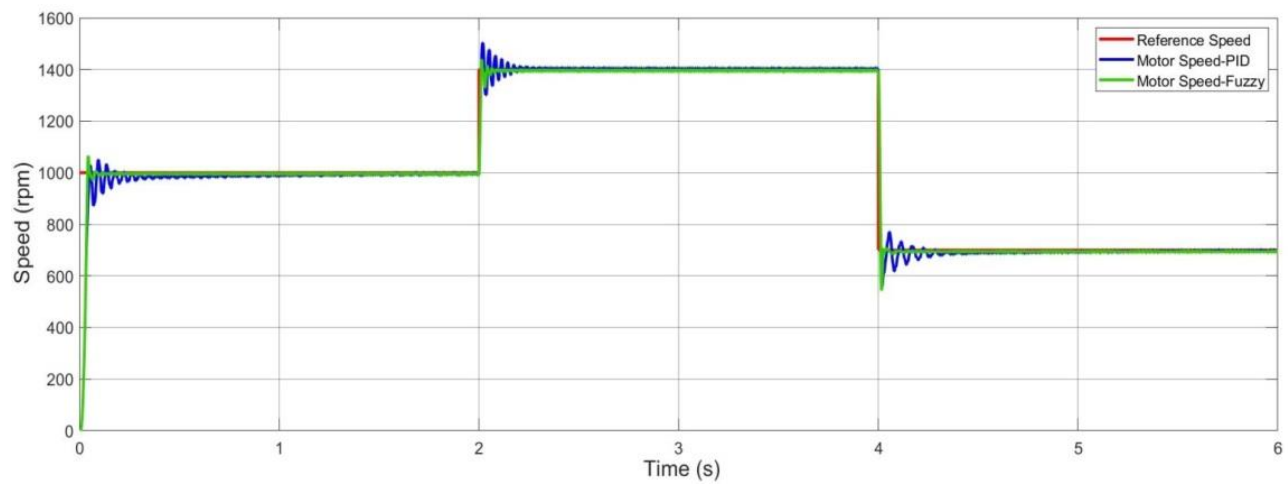

Fig. 9 Variations in speed response

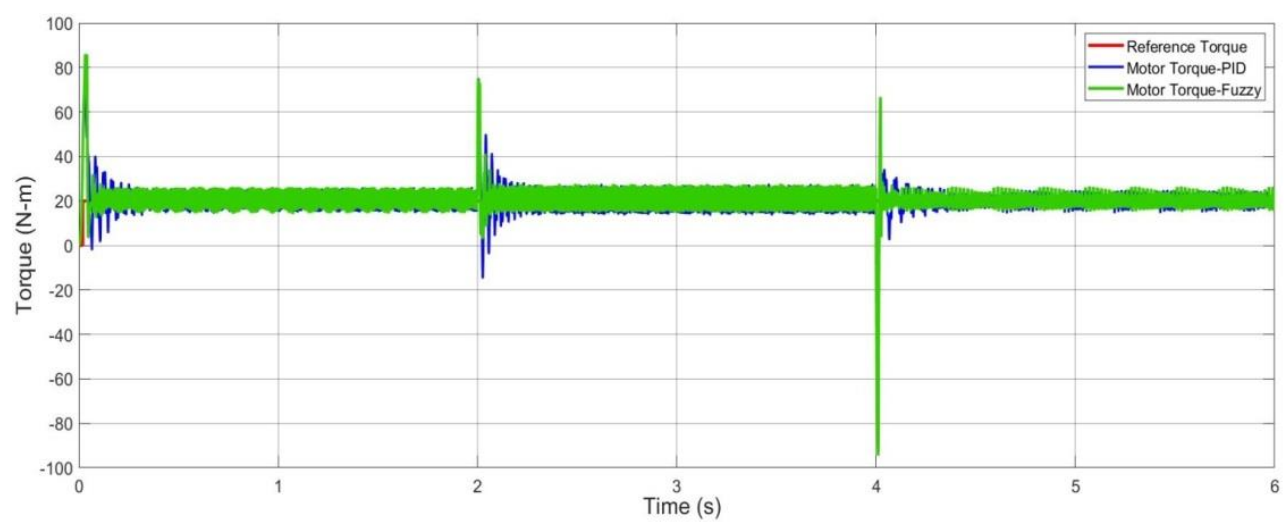

Fig. 10 Variations in torque response 


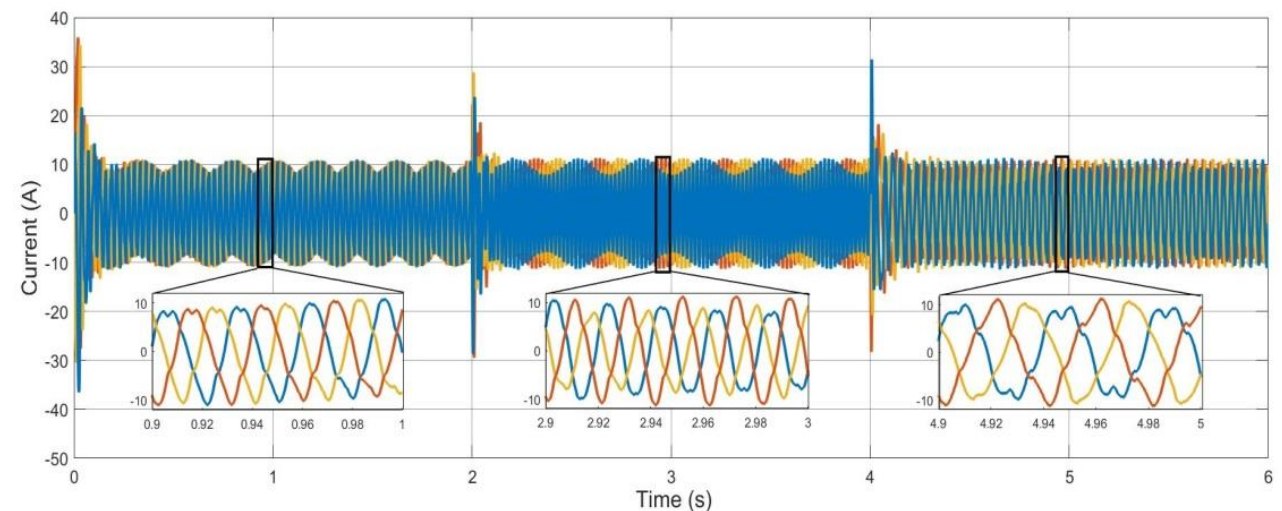

Fig. 11 Variations in stator currents using PID controller

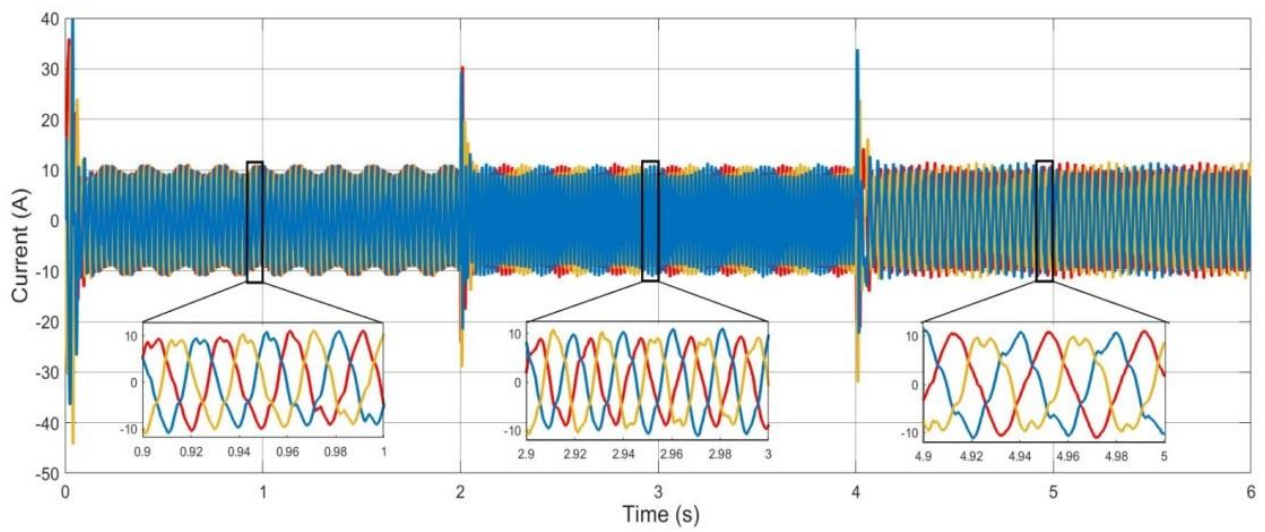

Fig. 12 Variations in stator currents using fuzzy logic controller

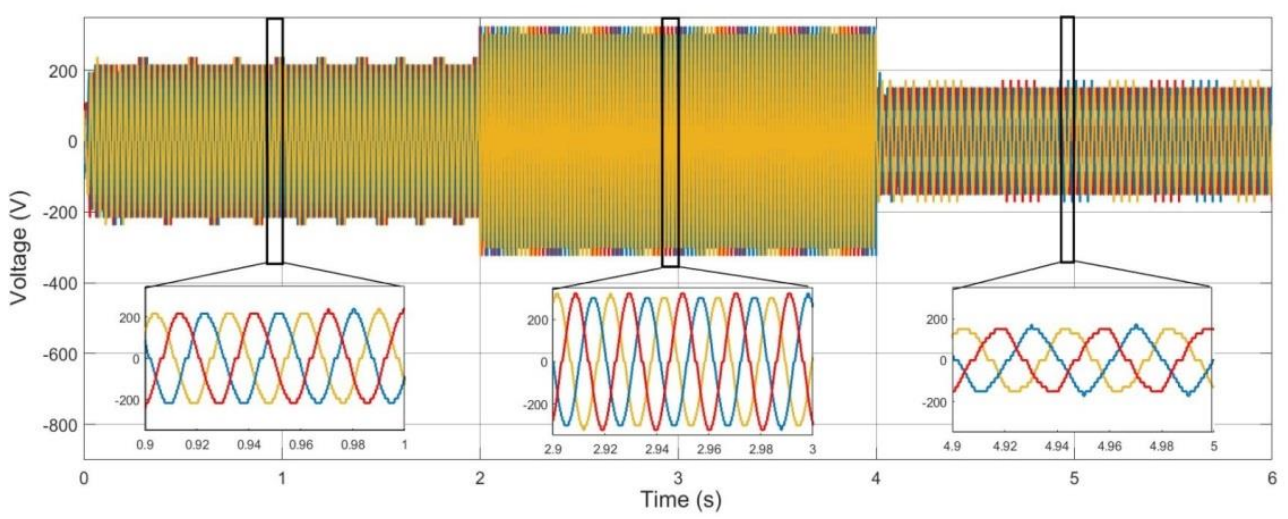

Fig. 13 Variations in MLI output using PID controller

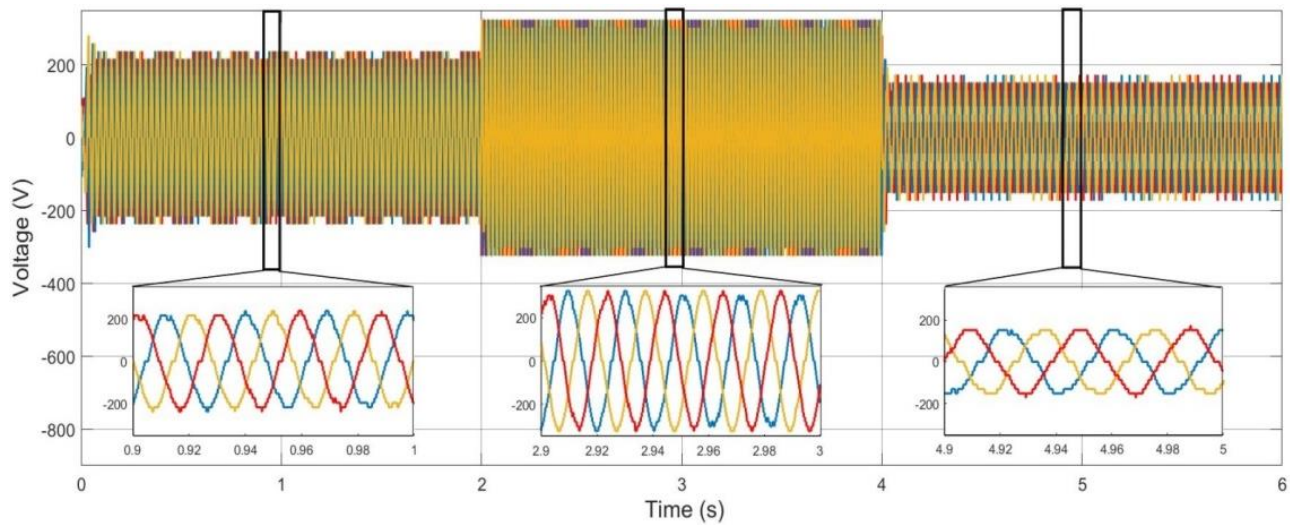

Fig. 14 Variations in MLI output using fuzzy logic controller

From the results obtained in case 1, the following are the observations made. The induction motor tracks the reference speed precisely using both PID and fuzzy logic controllers. Though the overshoots are observed in the performance of both controllers, the settling-time is observed to be lower while using the fuzzy logic controller than the PID controller. The fuzzy 
logic controller portraits a better response when the reference speed is changed. It tends to approach the new reference faster. The magnitude and the frequency of the output voltage of MLI have also changed with the reference speed. Table 2 provides the comparative analysis between the PID and fuzzy logic controller's performance for case 1.

Table 2 Comparative analysis for variable speed and constant load torque

\begin{tabular}{|c|c|c|}
\hline Parameter & PID controller & Fuzzy logic controller \\
\hline Rise time & $0.1 \mathrm{sec}$ & $0.1 \mathrm{sec}$ \\
\hline Settling time & $0.5 \mathrm{sec}$ & $0.2 \mathrm{sec}$ \\
\hline Overshoot & More & Less \\
\hline Speed of response & Slow & Quick \\
\hline Range of speed control & $600 \mathrm{rpm}$ to $1500 \mathrm{rpm}$ & $300 \mathrm{rpm}$ to $1500 \mathrm{rpm}$ \\
\hline
\end{tabular}

\subsection{Case 2: constant speed and variable load torque}

A constant reference speed of $1200 \mathrm{rpm}$ is given to the motor, and the load torque on the motor is changed stepwise from $5 \mathrm{~N}-\mathrm{m}$ to $30 \mathrm{~N}-\mathrm{m}$ at $t=2 \mathrm{sec}$. The changes in speed response (Fig. 15), torque response (Fig. 16), stator currents (Figs. 17-18), and MLI output (Figs. 19-20) are noted.

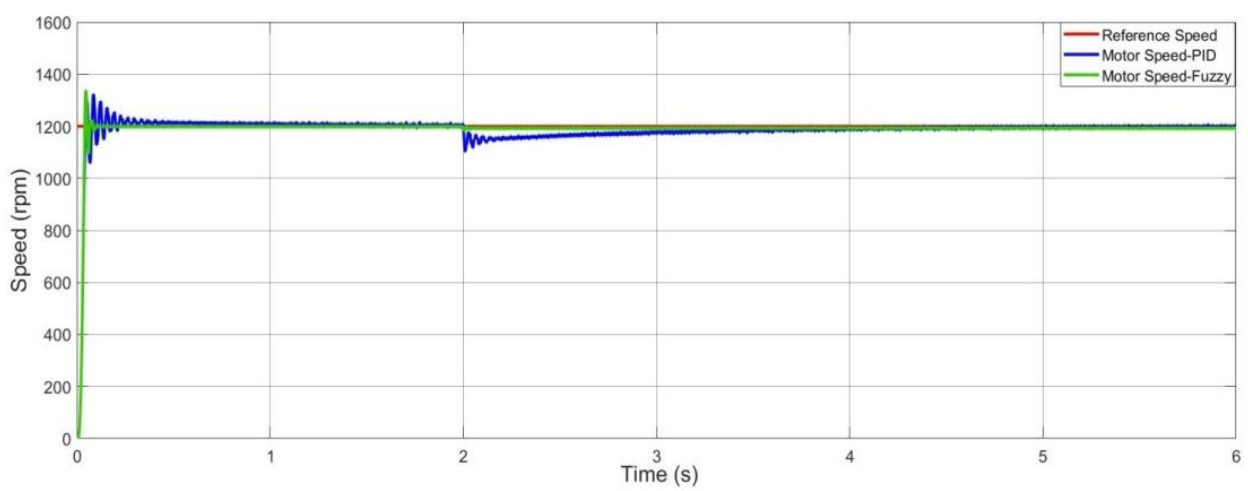

Fig. 15 Variations in speed response

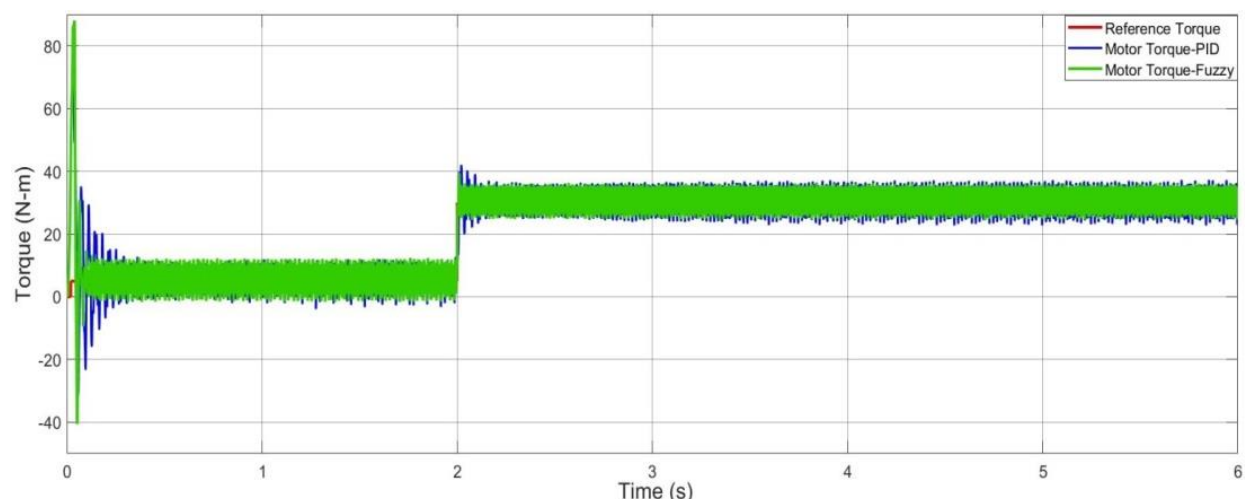

Fig. 16 Variations in torque response

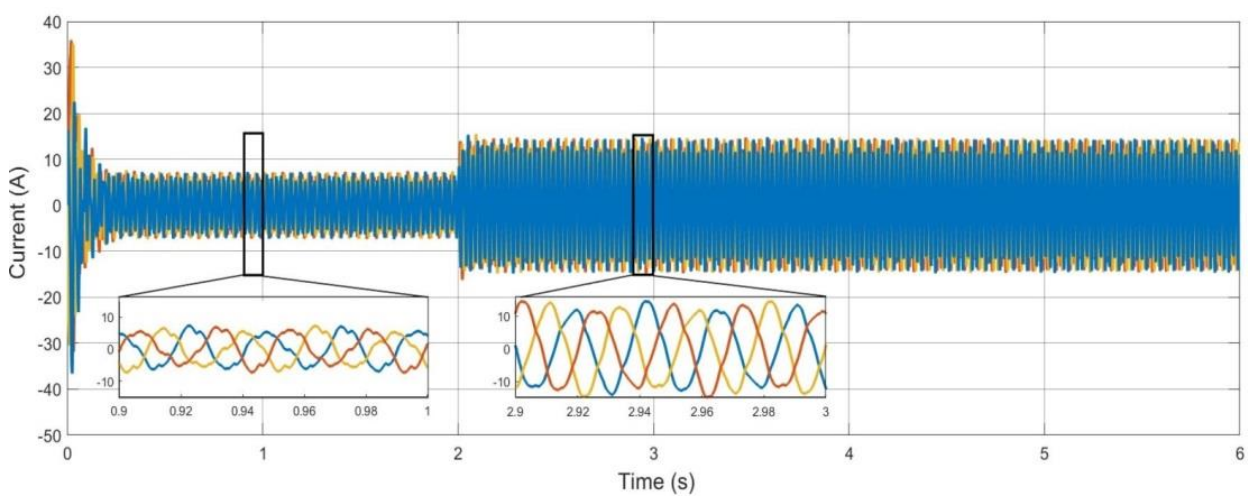

Fig. 17 Variations in stator currents using PID controller 


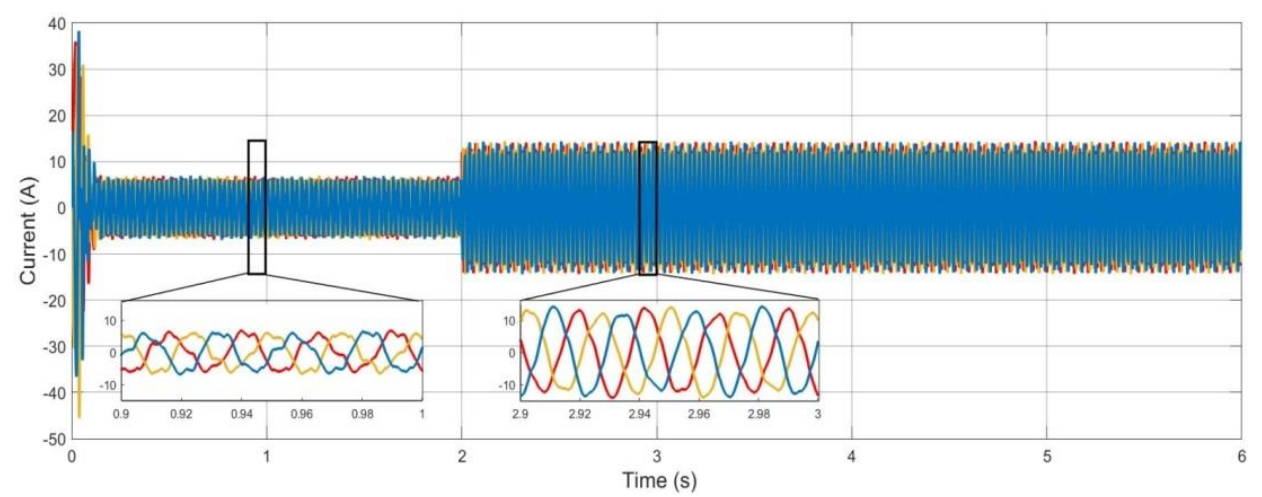

Fig. 18 Variations in stator currents using fuzzy logic controller

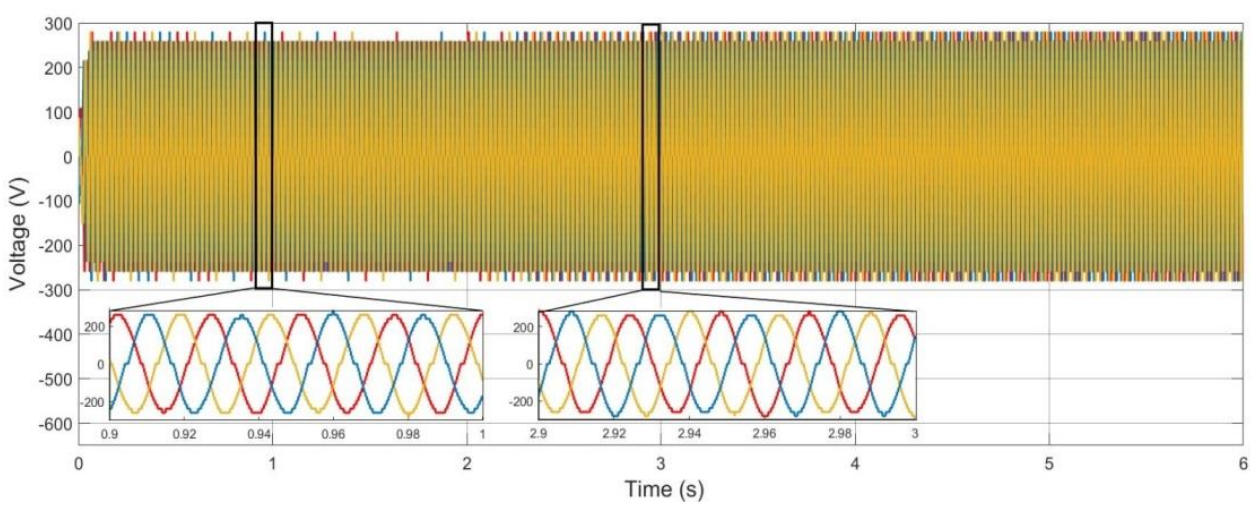

Fig. 19 Variations in MLI output using PID controller

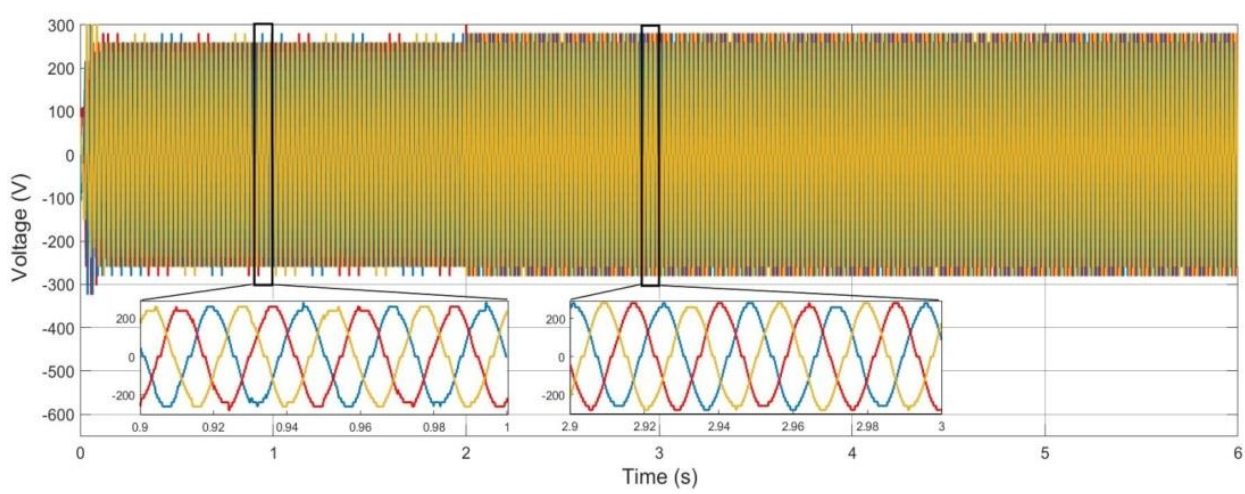

Fig. 20 Variations in MLI output using fuzzy logic controller

From the results obtained in case 2, the following are the observations made. The induction motor tracks the reference speed precisely using both controllers even when the torque is changed. As the load torque on the motor is changed, there is a disturbance in the motor speed. It is pronounced more when a PID controller is used as compared to the case when the fuzzy logic controller is used. The speed response due to the fuzzy logic controller shows almost negligible change when the load torque on the induction motor is changed. However, there is a small steady-state error for high load torque in fuzzy controller response which is almost negligible. In the torque response also, the oscillations are observed to be lower at starting and also at high load torque when the fuzzy logic controller is used when compared to the PID controller. The magnitude and the frequency of the output voltage of MLI have also changed with the load torque. Table 3 presents the comparative analysis between the PID and fuzzy logic controller's performance for case 2.

Table 3 Comparative analysis for constant speed and variable load torque

\begin{tabular}{|c|c|c|}
\hline Parameter & PID controller & Fuzzy logic controller \\
\hline Rise time & $0.1 \mathrm{sec}$ & $0.1 \mathrm{sec}$ \\
\hline Settling time & $3 \mathrm{sec}$ & $0.2 \mathrm{sec}$ \\
\hline Overshoot & More & Less \\
\hline Speed of response & Slow & Quick \\
\hline Range of torque control & $0 \mathrm{~N}-\mathrm{m}$ to $35 \mathrm{~N}-\mathrm{m}$ & $0 \mathrm{~N}-\mathrm{m}$ to $35 \mathrm{~N}-\mathrm{m}$ \\
\hline
\end{tabular}




\section{Conclusions}

In this study, a V/f closed-loop control scheme for MLI fed induction motors developed in MATLAB/SIMULINK is shown. A thirty-one-level MLI is employed. The model is simulated using two controllers (conventional PID and fuzzy-PID controllers) in two cases (reference speed change and load torque change).

From the results, it is evident that the magnitude of the torque ripples is reduced to a great extent as compared to the case when a three-level inverter is employed [3]. Since the induction motor is fed from the thirty-one-level MLI, which produces voltages of low harmonic distortion as compared to a three-level VSI, the harmonic distortion in the stator currents is also reduced. The power loss is reduced and hence the efficiency is increased as compared to the case when a two-level or a three-level inverter is employed.

Both the conventional PID and fuzzy-PID controllers provide a good response. The rise time is observed to be same for both controllers. However, the overshoots and settling-time are less when a fuzzy controller is used. The rotor speed tends to approach the new reference speed faster when the fuzzy controller is used than the PID controller. Torque ripples are also observed to be slightly lower in the case of the fuzzy controller.

Hence, this V/f control model of MLI fed induction motors can be employed in low, medium, and high power applications with the optimum usage of input power. From the results, the fuzzy logic controller shows better performance as compared to the PID controller. Hence, the PID controller can be replaced by the fuzzy logic controller.

\section{Conflicts of Interest}

The authors declare no conflicts of interest.

\section{References}

[1] A. Agrawal, R. S. Lodhi, and P. Nema, "A Review of Speed Control Methods of Induction Motors," IOSR Journal of Electrical and Electronics Engineering, vol. 13, no. 3, pp. 9-14, May-June 2018.

[2] A. Desai, S. Deshmukh, U. Chaugule, M. Bonde, and J. Satheesh, "Speed Control of 3-Phase Induction Motor Using V/f Method," Academia, vol. 7, no. 4, pp. 6224-6226, 2017.

[3] D. Jee and N. Patel, "V/f Control of Induction Motor Drive," Thesis, Department of Electrical Engineering, National Institute of Technology, Rourkela, Odisha, 2013.

[4] A. Chitra, W. R. Sultana, J. Vanishree, S. Sreejith, S. Jose, and A. J. Pulickan, "Performance Comparison of Multilevel Inverter Topologies for Closed Loop V/f Controlled Induction Motor Drive,” Energy Procedia, vol. 117, pp. 958-965, June 2017.

[5] R. Bharti, M. Kumar, and B. M. Prasad, "V/F Control of Three Phase Induction Motor," International Conference on Vision Towards Emerging Trends in Communication and Networking, pp. 1-4, March 2019.

[6] C. U. Ogbaku and M. U. Agu, "Effects of Load and Speed Variations in a Modified Closed Loop V/F Induction Motor Drive," Nigerian Journal of Technology, vol. 31, no. 3, pp. 365-369, 2012.

[7] I. Colak, E. Kabalci, and R. Bayindir, "Review of Multilevel Voltage Source Inverter Topologies and Control Schemes," Energy Conversion and Management, vol. 52, no. 2, pp. 1114-1128, February 2011.

[8] A. El-Hosainy, H. A. Hamed, H. Z. Azazi, and E. E. El-Kholy, "A Review of Multilevel Inverter Topologies, Control Techniques, and Applications," 19th International Middle-East Power Systems Conference, pp. 1265-1275, December 2017.

[9] I. E. Tashiwa, G. D. Dung, and B. S. Adole, "Review of Multilevel Inverters and Their Control Techniques," European Journal of Engineering Research and Science, vol. 5, no. 6, pp. 659-664, June 2020.

[10] A. Dubey and A. K. Bansal, "Cascaded H-bridge Multilevel Inverter," International Journal of Control Theory and Applications, vol. 9, no. 7, pp. 3029-3036, 2016.

[11] R. Agrawal and S. Jain, "Comparison of Reduced Part Count Multilevel Inverters (RPC-MLIs) for Integration to the Grid," International Journal of Electrical Power and Energy Systems, vol. 84, pp. 214-224, January 2017. 
[12] K. A. Shilpa, M. Revathi, and K. R. Sudha, "Design and Implementation of Thirty One Level Multilevel Inverter," International Conference on Smart and Intelligent Systems, pp. 547-555, February 2021.

[13] V. Varun, B. Govindarajan, and S. Nayak, "Speed Control of Induction Motor Using Fuzzy Logic Approach,” Thesis, Department of Electrical Engineering, National Institute of Technology, Rourkela, Odisha, 2011.

[14] T. D. Dongale, S. R. Jadhav, S. V Kulkarni, T. G. Kulkarni, R. R. Mudholkar, and M. D. Uplane, "Performance Comparison of PID and Fuzzy Control Techniques in Three Phase Induction Motor Control," International Journal on Recent Trends in Engineering and Technology, vol. 7, no. 2, pp. 5-8, 2012.

[15] S. Pati, A. Panda, and S. Mohanty, "A Comparative Performance Study of Scalar Controlled Induction Motor Using PID Controller and Fuzzy PID Controller," International Conference on Circuits, Power, and Computing Technologies, pp. 904-909, March 2014.

[16] S. Pati, M. Patnaik, and A. Panda, "Comparative Performance Analysis of Fuzzy PI, PD and PID Controllers Used in a Scalar Controlled Induction Motor Drive," International Conference on Circuits, Power, and Computing Technologies, pp. 910-915, March 2014.

[17] M. Vahedpour, A. R. Noei, and H. A. Kholerdi, "Comparison Between Performance of Conventional, Fuzzy and Fractional Order PID Controllers in Practical Speed Control of Induction Motor," 2nd International Conference on Knowledge-Based Engineering and Innovation, pp. 912-916, November 2015.

Copyright $\odot$ by the authors. Licensee TAETI, Taiwan. This article is an open access article distributed under the terms and conditions of the Creative Commons Attribution (CC BY-NC) license (https://creativecommons.org/licenses/by-nc/4.0/). 